\title{
Research on Mathematical Modeling of the Motion of Super - Large Double - Propeller and Double - Rudder Container Ships in Harbor
}

\author{
Yongxiang Li \\ Shandong Jiaotong University, Weihai, Shandong
}

Keywords: Twin-screw twin-rudder; mathematical model; MMG; port; nonlinear feedback

\begin{abstract}
With the increasingly expansion of container ships and the relatively bad sailing environment, in order to improve the safety of ship navigation, the requirement of ship's operation level is gradually improving globally. Super large twin tank container ships come into being, and the continuous development of the maneuverability research becomes more and more important. In order to improve the safety of super large container ship propeller twin rudder, this paper conducted in-depth study on its operating performance, established a mathematical model on behalf of the maneuvering characteristics of super large twin propeller twin rudder ships.
\end{abstract}

\section{Introduction}

With the deepening of international economic exchanges, international trade is more prosperous and the large-scale development of container ships has been promoted. The continuous progress of science and technology, the more rapid, specialization and modernization, as well as the container transportation damage rate is low, the future development of large-scale container ship is becoming more and more obvious. The increasing pressure ship, the paving, port and many other waters into relatively shallow waters, only additionaldepth small sailing in these waters of the ship, and the number of ships in such waters, traffic density, which makes the ship maneuvering space reduced, relatively increased risk of damage to the ship and offshore facilities. Moreover, with the increasing speed of ships, the operation of large single propeller single rudder ships in port is more and more complex, which brings a series of difficulties to ship maneuvering and navigation safety. Pressure

In order to solve the above problems, to improve the ship maneuverability, reduce berthing time dependence on the tug, rope and chain, reduce the cost of ship berthing, equipped with multi propellers and multi tank system came into being, the ship which is equipped with twin energy system is the most widely. And with the reduction of the number of crew, the ship is large and twin system equipped with use, which makes the ship port operation more difficult and complex. Therefore, in order to improve the safety coefficient of the ship, in-depth study in super large twin ships can exercise performance, to establish accurate mathematical model reflecting the super large twin propeller twin rudder ship maneuverability is very necessary, but also has important theoretical significance and engineering significance.

At present, because of the complexity of the dual prize and dual energy ship, there is not a complete system similar to single propeller and single rudder ship motion mathematical model. Therefore, based on the super large twin-screw twin-rudder ship motion mathematical model is studied, the research achievements of comprehensive utilization of domestic and foreign scholars in this field, to establish appropriate harbor large double double award to the mathematical model of ship motion. This paper established the precise ultra large twin-screw twin-rudder container ship motion mathematical model can be used for ship motion simulation, and then the Ship Maneuverability Prediction, but also can be used for the mathematical model of improved sea simulator on ship double double award, but also on the basis of this model, the design of various control algorithms to solve ship automatic berthing and other issues.

\section{Super large twin-screw twin-rudder ship motion mathematical model}

The MMG in the hydrodynamic model is a modular mathematical model, which includes the 
hydrodynamic forces between the three parts, such as hull, propeller and rudder. The fluid power has clear physical meaning and parameters are easy to correct. This chapter is based on the separation of MMG modeling method, under the assumption that the ships sailing in the waters of the infinite case, ignore the influence of external environment on the ship, establish the mathematical model for hull, propeller and ship, then considering $\mathrm{H}$ mutual interference, so as to establish a large double propeller twin rudder ship motion mathematical model. Pressure

A twin-screw twin-rudder ship, with 2 propellers and 2, symmetrically mounted at the stern under water on both sides of the central keel. Double sculls can ship in rotation, in the turning circle outside of the propeller and rudder are called outer propeller and external energy, otherwise known as the inner propeller and internal energy. According to the direction of rotation of the propeller, two ships can be divided into external rotation and internal rotation of two propellers. When the outer spiral 2 spiral pulps are turning, from the end of the ship, the left propeller turns left, the right propeller turns right, and vice versa.

Ship navigation is a propulsion power of a ship, which is used to overcome the resistance of water, keep the ship at a certain speed and maintain the ship's maneuvering motion. Therefore, the mathematical model of propeller is an important part of ship motion modeling. Propeller thrust coefficient can be calculated according to the corresponding map according to the propeller type of the real ship. Even if the real ship propeller profile is not available, the thrust coefficient of the propeller can be calculated by using the series of real propellers. The thrust coefficient of different types of propellers is generally different, enough to meet the requirements of the simulation precision, so the atlas can be selected according to the requirements in the actual simulation.

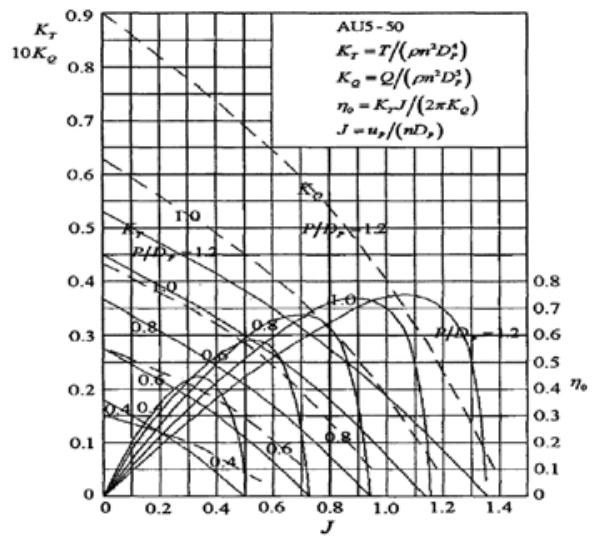

Figure 1 Open water propeller characteristic curves

At present, many methods can be used to estimate the co flow coefficient of propeller, and the results obtained by different methods are very different. In order to confirm the application of the regression formula and comparative analysis of $\mathrm{Xu}$ who satisfied estimation of all kinds of ship measured data and the regression formula for the estimation of the regression formula of ship propellers, the values are close to the measured results, the best formula of Hank Fischer, Baptista Mir of formula when the ship; but the square coefficient is small, all vary greatly. So relatively speaking, Hank's formula is better.

\section{Mathematical model of ship movement in port}

Sailing ships in the harbor are low speed, generally considered to maintain energy efficiency below the speed of speed is low speed, low speed marine domain maneuverability research is a very difficult work, and the mathematical model of ship motion speed field is the basic research of lowspeed maneuverability.

The large ship makes relatively shallow water increased, and when the ship sailed to the waters from the waters of there will be resistance increases, speed decrease, deflection run phenomenon, brings some difficulty to the ship maneuvering. In order to predict the maneuverability of ships in shallow water, based on MMG in deep waters, it is popularized and applied to shallow water field 
by modifying the model parameters.

The actual ship suffered wind pressure and torque is directly related to the relative wind and the relative wind boat angle refers to the wind speed, on the boat to feel the wind, is attached on the coordinate system of variable; absolute wind and wind direction is absolutely ship actual meteorological environment, is the inertial coordinate system variables, as shown in figure 2.

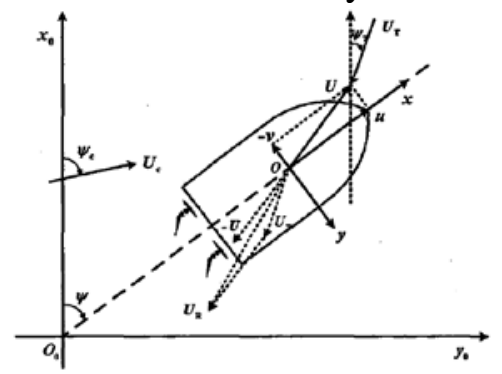

Figure 2 Disturbance diagram of wind and flow

A sailing ship with, especially in the harbor, will be affected by the wind as resulting in the deviation of a ship or violent shaking, endanger the safe navigation of the ship, so a mathematical modeling of Ship Manoeuvring Motion should establish a mathematical model to describe the wind quite accurately.

In order to study the harbor large double shuangtuo container ship maneuvering performance award, the "Maersk Marie" as the simulation object, the harbor has 19.2 deep m assumes that the (1.2 times the ship's draught), harbor large enough ships at low speed to carry out simulation test, the spiral 30RPM and initial speed of $9.2 \mathrm{rpm}$ for the kn.

The keeping control of ship course is the core of marine transportation automation. Because of the excellent stability of the PID controller, it is widely used in the actual navigation of the ship. For ship course keeping system, the model adopts the double harbor super large award shuangtuo container ship motion mathematical model; PID controller is used in controller, combined with the related control strategies for its improvement. Pressure

Based on the idea of MMG separation modeling, the mathematical model of ship motion is established. The model is more complex and difficult to be directly used for controller design. Therefore, this paper uses the idea of hybrid modeling and simulation to design PID controller. Because of this model and response model is used to describe the motion of the ship specialization are similar in a certain extent, so the paper ship parameters according to the "MaerskMarie" build ship advised response model, then the model with first-order closed loop gain shaping controller, PID controller the design for the control of the port of super large double double award can ship motion mathematical model of container, ship course keeping simulation test. Pressure.

Ship motion mathematical model of two order transfer function type, which is the famous Nomoto model, is a series of simplified Zuohou on the whole Wang ship motion mathematical model, the controller design is widely used in automatic energy. As shown in Figure 3.

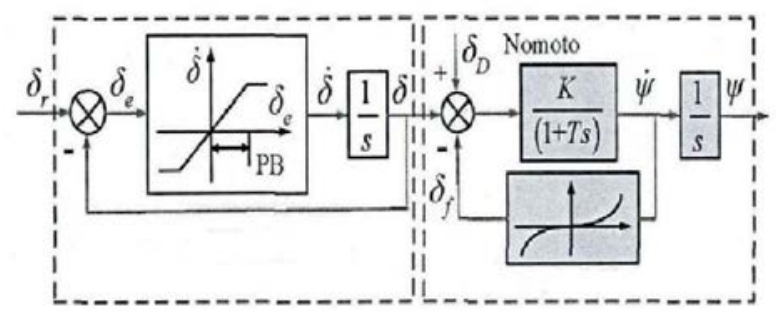

Figure 3 Mathematical model of nonlinear ship motion

Closed loop gain shaping algorithm is the direct use of nuclear expression controller system design of closed function matrix, refers to the use of the mixed sensitivity control algorithm and control with great benefits, engineering significance of the 4 parameters directly constructed complementary sensitivity function $\mathrm{R}, \mathrm{R}$ and $\mathrm{S}$ have correlation with sensitivity function, thus indirectly constructed, then launch controller mow. Among them, the 4 parameters of engineering 
significance are the maximum singular value, the bandwidth frequency, the pass slope and the closed loop spectrum peak.

In the design of PID controller, using the ship motion model of Nomoto, and in the simulation with the port of super large container ships double award double motion mathematical model, the equivalent mathematical model of the model perturbation, and the control effect can still meet the requirements of the PID controller has good robustness. In standard feedback system, how to find a stable and well controlled controller is the main research work. But the main task of this section is to prove that the performance of nonlinear feedback control is better under the same controller's situation. The influence of nonlinear feedback on the system under the action of sinusoidal function is studied by mathematical derivation under $\mathrm{W}$.

The wind equivalent cabin angle obtained by empirical formula or mechanism formula is consistent with the concept of rudder angle in ship maneuvering. They are quite similar in magnitude. Therefore, this method can also be used to describe the mathematical model of wind.

Comparisons show that through the infinite water under the "Maersk Marie" ship test results with Matlab simulation results, the fitting degree of dextral back to left back, left back of simulated and real ship test the maximum error is $16.5 \%$, can meet the accuracy requirement of the project. The ship motion mathematical model is established through the analysis of the source of the cause of this error is that approximate substitution includes ship parameters, such as the floating distance of ship hull coordinate origin distance, additional resistance estimation, approximate hull hydrodynamic approximation. The number of positive Repair Guide

No influence on the airflow or airflow, vessel cycle Qiaozhen test results accord with the actual situation of the sea, can reflect the ship maneuverability so skillfully, the large double or dual energy model of container ship motion mathematical can reflect the appropriate handling performance of harbor ship shuangtuo double award. Pressure

Based on the model established in this paper, the ship course keeping control problem is studied. The closed loop gain shaping algorithm and nonlinear feedback control algorithm are used to design the controller, and satisfactory control results are achieved. It can be seen that all kinds of control algorithms can be designed on the basis of the model established in this paper, in order to solve the related problems of ship motion control. Therefore, the mathematical model of the super large double - prize double - cabin container ship movement established in this paper has important theoretical and engineering significance. Pressure

\section{References}

[1] Hu Xiaofang, Chen Songlin. The propeller load characteristics of Twin-Screw Ship Maneuverability Prediction Based on the research of ship. China, 2014

[2] Wang Shijiang. Numerical and mathematical expression of the multi mode Atlas of propeller. Times report: Academic Edition, 2012

[3] Sheng Zhenbang, Liu Yingzhong. The principle of ship. Shanghai: Shanghai Jiao Tong University press, 2011

[4] Guo Chunyu, Wang Chao, Changxin. The theory and method of the performance prediction of paddle steering interference. Harbin: Harbin Engineering University press, 2015

[5] Party Nianjian. Effect of shallow water on the berthing. Navigation technology, 2014

[6] Zhang shows a claim. An autopilot control algorithm driven by a sinusoidal function of heading deviation. China voyage, 2016 